\title{
Grand Challenges in Urban Science
}

\author{
Marina Alberti* \\ Department of Urban Design and Planning, University of Washington, Seattle, WA, USA
}

Keywords: urban science, cities, complexity, big data, human-natural systems

Cities face a grand challenge: they must rethink themselves in the context of planetary change. Global urban development is a prominent feature of our new geological epoch, the Anthropocene (Crutzen and Stoermer, 2000; Ruddiman, 2013). Though scientists disagree on exactly when the Anthropocene began (Ellis et al., 2013; Foley and Lewin, 2013), there is strong evidence of humans' profound effects on planetary evolution. Over the past century, the "great acceleration" of human activities associated with rapid urbanization has initiated fundamental ecosystem shifts that far exceed the natural range of variability exhibited during the Earth's previous half-million years (Steffen et al., 2015). These shifts represent uncharted territories for urban scholars, and the assumptions made by previous dominant theories and models (i.e., that the urban systems will respond predictably to urban pressures and to the feedbacks from environmental changes) are built upon structures of evidence of a world that no longer exists. The emergence of complex interactions among human, natural, and technological systems and the uncertain trajectories that characterize urban futures require that urban scientists critically review their assumptions and expand their capacity to ask new questions (Alberti, 2016).

Cities, now home to most of the world's population, generate over $90 \%$ of global economy, produce up to $75 \%$ of greenhouse gases, and consume $75 \%$ of energy and $60 \%$ of global drinking water (UN-Habitat, 2016). Urbanization is driving systemic changes in socioeconomic (Bettencourt et al., 2007; Bloom et al., 2008; Glaeser, 2011; Angel, 2012) and ecological systems (Alberti, 2008, 2016; Grimm et al., 2008a,b; McDonnell et al., 2009; Niemelä and Breuste, 2011; Forman, 2014) by accelerating rates of interactions among people and places, multiplying numbers and strengths of connections, and expanding the spatial scales and influences of human activities to global levels (Young et al., 2006). It is increasingly evident that cities amplify the consequences associated with globalization such as the movements of people and products, access to, and disruption of natural resources, and threats to biodiversity (Lenzen et al., 2012).

The physical configurations of urban settlements are also evolving, as social and technological accelerations promote dissolution of boundaries among areas traditionally labeled "urban," "regional," "suburban," and "rural" (UN-Habitat, 2008). Over the last century, the polycentric city structure has emerged as centralized cities have become increasingly connected to satellite cities and rural hinterlands, giving rise to the metropolises, the multicentric megacities, and ultimately our modern networked megaregions (Pickett and Zhou, 2015). In concert with these structural changes, the function of cities has also evolved. Infrastructural and technological progress, the emergence of service- and knowledge-based economies, and the accompanying increase in teleconnections, interdependence, and regional and global integration are evidences of cities' rapid shift from industrial productivity toward economic diversification (Ross, 2009; McGrath and Shane, 2012; McHale et al., 2015; Pickett and Zhou, 2015).

Despite this increasing global interdependence and integration, today's urbanizing regions remain highly diverse with regard to physical structures, social organizations, biophysical environments, and political contexts. While there are important commonalities across many metropolitan regions, there is also great diversity across regions and across cities of differing sizes. Today, the fastest growing urban agglomerations are medium-sized cities and cities with less than 1 million inhabitants that are located in the global south. The UN (2014) estimates that about half of urban dwellers worldwide live in relatively small settlements of less than 500,000 inhabitants, as compared 
to the 1 in 8 who live in megacities of 10 million inhabitants or more. These settlements have high relative rates of population growth and poverty, and inadequate infrastructure and governance to face rapid growth (Birkmann et al., 2016).

Convergence and interactions of functional, structural, and social changes result in challenges of unprecedented complexity for city governments as they attempt to provide critical services (Bettencourt et al., 2007; Grimm et al., 2008b). In the emerging economies, where most urban growth is occurring, such transitions, in concert with poor planning, have driven the emergence of informal settlements such as slums (Marx et al., 2013). The risks and opportunities posed by the urban transition are yet to be fully defined, and thus far, they have not been the focus of much research. Population growth, displacement and migration, economic fluctuations and instabilities, disparities and segregations, inadequate or aging infrastructure, pollution, and health threats associated with increasingly frequent extreme climate events are a few of the most pressing problems (UN-Habitat, 2016). Establishing healthy urban conditions through planning, design, and management, while ensuring a resilient and equitable future for humanity, requires a new understanding of how the myriad elements converge and interact to form and influence urban functions and dynamics (McPhearson et al., 2016a). Given the uncertainties surrounding these complex interactions, urban decision makers need reliable empirical evidence, innovative decision-making tools, and novel approaches: a whole new science (Rosenzweig et al., 2010).

\section{A SCIENCE OF CITIES}

Despite the long history of cities as subjects of observation, the systematic study of urban structures began only a hundred years ago, since which time, scholars have advanced a variety of framing concepts and general theories (Geddes, 1915; Burgess, 1925; Mumford, 1925; Park et al., 1925; Lynch, 1961; Alonso, 1964; Forrester, 1969; Boyden et al., 1981; Portugali, 2000; Batty, 2005; Bettencourt, 2013). Cities have been compared to living systems (Geddes, 1915), biological organisms (Odum, 1971), and ecosystems (Odum, 1975). Various efforts to describe the city as an economic, social, or political system have depicted the economic, social, or political dynamics, but none has attempted to understand the interactions between those dynamics and the ecological dimensions. Half a century ago, Jacobs (1961) referred to the city as "organized complexity" Since then, the view that cities are complex systems has emerged as a new challenge and a new frontier for science (Batty, 2005, 2013). Luis Bettencourt and Geoffrey West at the Santa Fe Institute have been working on formalizing a new quantitative understanding of urban function (Bettencourt and West, 2010). By examining a large set of data on diverse aspects of urban regions, they observed that cities exhibit scaling relationships similar to those that biologists use to describe organisms' molecular, physiological, ecological, and life-history attributes (Bettencourt et al., 2007).

Scientists studying cities as complex systems are eager to identify universal governing principles that could guide development of a predictive theory of urban growth and change, which would inform urban management decisions. Despite remarkable progress in the study of urban systems over the past few decades, however, a unified science of cities as complex coupled human-natural systems has yet to be achieved. Urban science lacks a theory of human settlements and their functions that is grounded in empirical evidence of how the many dimensions interact with one another (Alberti, 2016). Do thriving cities share a particular set of common properties? Can we identify a reliable array of features that explains such cities' vitality and well-being? Are there factors, such as size, density, or form that best correlate with the health of a city? What properties enable cities to adapt, change, and evolve? What makes a city resilient?

To understand how cities emerge, function, and evolve, we must study urbanization as a process that simultaneously transforms places, populations, societies, and the environment (Batty, 2013; Solecki et al., 2013). Despite early conceptualizations of urban systems as complex dynamic systems (Batty, 2005), empirical explorations of the relationships between agent interactions and varying patterns of urbanization are still at an early stage (Alberti, 2016). The pattern of urbanization is the result of complex interactions among multiple heterogeneous agents across multiple scales (Seto et al., 2012). Agents are households, businesses, real estate developers, and governmental and non-governmental organizations that make decisions at the individual, community, city, and regional levels. These decisions directly and indirectly affect the natural and built environment, which in turn influence urban dwellers and their quality of life. Agents are also the diverse formal and informal networks that are emerging within and across cities, expanding the capacities of cities to address emerging problems. An example is C40, a network of the world's megacities created in 2005 to tackle climate change.

Today's unprecedented availability of highly disaggregated data and measurements provides novel opportunities to discover universal rules by which cities work and innovate. But, big data and new data analytics answer only the questions that we are able to formulate. The challenge is to turn the unprecedented floods of data into new knowledge about urban systems and novel insights for their effective management (Alberti, 2016). How do we expand our lens of inquiry such that we are able to formulate new questions? Emerging urban challenges-to achieve equitable access to resources and services, promote health, design and implement energy-efficient systems, adapt to climate change, and increase livability - can be addressed only by an integrated approach that acknowledges the intricate and complex nature of our cities.

We have made remarkable progress in recent decades in studying the diverse patterns of urbanization (Batty, 2013) and their impacts on ecological systems. Yet the myriad interactions among socioeconomic and ecosystem processes in urbanizing regions remain poorly understood. Empirical studies of the mechanisms linking urban dynamics to socio-ecological change and evolution are limited and idiosyncratic (Alberti, 2016; McPhearson et al., 2016a). Most empirical research still disregards the preeminence of cities as the setting for human economic and social life. Gaps in problem specification and differences in methodological approaches across disciplinary boundaries, as well as variable 
definitions of terms such as urban, urbanization, and city hamper efforts to develop a common theory and research framework. But, advances in complex systems science and emerging studies of coupled human-natural systems are beginning to provide powerful tools for uncovering general properties of cities (Bettencourt, 2013). These insights will serve as starting points for investigations of the mechanisms underlying diversity in urban societies and environments. Building on such advances, urban scholars have unique opportunities to integrate multiple perspectives to better understand complex socio-ecological dynamics, their feedbacks, and the effects of interactions on innovation in urban and urbanizing regions.

\section{URBAN SCIENCE CHALLENGES AND OPPORTUNITIES}

- What drives urban evolution? Are there common underlying mechanisms and universal laws that govern urban development, growth, and change?

- What are the emerging patterns of urbanization throughout the globe, and what are the plausible urban scenarios for the future? How will emerging patterns of urbanization influence key determinants of ecological and human well-being?

- What opportunities and challenges do new technologies, realtime sensors, and big data provide for tackling urban issues?

- What are the most promising innovative technological and institutional solutions for transitioning to sustainable patterns of urban development?

- What kinds of cities do we want to live in? How can we direct urban change toward realization of such desirable future cities?

Urban systems represent a global phenomenon. And their multiple expressions can be viewed as microcosms of the urbanizing planet, providing urban scientists an opportunity to explore the dynamics of socio-ecological systems and assess different potential planetary trajectories (Grimm et al., 2008a). Understanding the relationships between urbanization and the well-being of humans and the environment is critical to generation of a theory of urban sustainability and resilience (UN-Habitat, 2016). Strategic decisions about urban planning and investments in infrastructure require synthesis of the complex and evolving knowledge of how coupled human-natural systems work. Only a new collaboration among scholars from diverse disciplines can develop a research agenda that will deliver a shared framework and generate a productive knowledge synthesis, connecting recent advancements in complex systems science, economics, ecology, evolutionary biology, engineering, and urban design and planning. Such synthesis is essential to transforming the study of cities into an integrative urban science to address the challenges confronting humanity in an urbanizing world.

Modeling and simulation have emerged as important tools for advancement of knowledge synthesis in urban science. New approaches for strategic foresight can also further address the limitations of prediction tools in dealing with high levels of uncertainty. The emergence of big data and rapid development in high-resolution monitoring instruments and computing power have the potential to provide planners with new capacity to anticipate and prepare for the future (Masson and Knutti, 2011). Diverse modeling platforms are advancing new concepts and methods-ranging from network science to machine learning - to integrate diverse data streams. Simulation models that more realistically represent heterogeneous human behaviors and complex decisions can more effectively support both short- and long-term urban planning (Alberti and Waddell, 2000; An, 2012).

Current computer models of human interactions with biophysical processes, while increasingly sophisticated, still only provide crude representations of human activities, and are particularly poor at characterizing systems with multiple feedbacks (Victor, 2015). Thus far, hypotheses about the emergent behaviors of coupled human-natural systems have not been formally tested. Modeling such hypotheses is difficult, given the array of interacting factors at play. Drivers such as climate change, economic development, urban patterns, built infrastructure, and planning interact across multiple spatial and temporal scales, resulting in the emergence of regime shifts, of which flooding, loss of biodiversity, and economic reorganizations are a few examples. While any one driver-effect relationship may be reasonably modeled, integration of multiple domains is far more challenging: interactions are often non-linear, and threshold effects, discontinuities, and compounding effects prevail within domains of interest. Capturing such non-linearity-and the underlying interactions-and detecting proximity to critical thresholds demands development of new techniques. Furthermore, several feedback mechanisms are seen in the setting of interactions within and between biophysical and urban processes: negative dampening forms tend to stabilize systems (e.g., real estate markets), while positive forms promote unstable conditions and catastrophic changes (e.g., extinction of species).

Despite important progress made in modeling dynamic, multi-agent social and ecological systems, simulating emergent behaviors and predicting long-range futures remain significant research challenges because the interactions between drivers are highly complex and uncertain. Modeling approaches that encapsulate agent-level processes and spatially explicit dynamics will be much more likely to reflect the natures of these emergent properties than will abstract, aggregate approaches (Verburg, 2016). Furthermore, the evolutionary trajectories of urban development and ecosystem processes are shaped by prior conditions, but many standard modeling approaches assume cross-sectional equilibrium conditions, and are therefore insensitive to path dependence. These present unprecedented opportunities to answer complex cross-disciplinary questions about urban systems.

The rapidly maturing "Internet of Things"-an extensively networked deployment of sensors and information technologies-opens new avenues for conceptualization and realization of cities that are efficient, sustainable, equitable, and livable (Townsend, 2013; Kitchin, 2014; Ratti and Claudel, 2016). Local governments and agencies are employing big data and analytics technologies to optimize infrastructure management and service delivery. Connections and transparency between users and service providers already relies on digital and mobile technologies, and adoption of enabling technologies has emerged as a potent 
shaper of human behavior patterns (e.g., the use of social media via smart phone apps for real-time communication to emergency responders during disasters). At larger scales, novel technologies provide new opportunities for businesses to experiment with promising new economic models, which can maximize their efficiency, resulting in success that can translate as additional resources and new income for city residents [President's Council of Advisors on Science and Technology (PCAST, 2016)]. Building on the unprecedented opportunities that big data offer to understanding the mechanisms driving urban systems will allow urban scientists to inform development of innovative technologies and planning strategies for transitioning toward sustainable and resilient cities.

Urban scientists have the opportunity to play an important role in providing the knowledge and laying the groundwork for such transitions (McPhearson et al., 2016b). For countries to succeed in meeting the $\mathrm{CO}_{2}$ emission reduction targets established by the Climate agreement in Paris (COP21) and in implementing the New Urban Agenda adopted at Habitat III in Quito, Ecuador (October 2016), urban regions will need to take significant steps in transitioning to low-carbon economies and sustainable pathways. Strategies to move rapidly and effectively in such directions must be based on the best available scientific evidence. Whether urban scientists will be heard depends, in great part, on our capacity to both achieve rapid progress in the field and establish a new partnership between science and society (Acuto, 2016).

\section{A NEW JOURNAL FOR A NEW URBAN SCIENCE}

Urban science is an emerging field that is poised at the intersection of the social, natural, and data sciences (Batty, 2013; Bettencourt, 2013; Solecki et al., 2013; Alberti, 2016; McPhearson et al., 2016a). It applies an interdisciplinary approach for

\section{REFERENCES}

Acuto, M. (2016). Give cities a seat at the top table. Nature 537, 611-613. doi:10.1038/537611a

Alberti, M., and Waddell, P. (2000). An integrated urban development and ecological model. Integrated Assessment 1, 215-227. doi:10.1023/A:1019140101212

Alberti, M. (2008). Advances in Urban Ecology: Integrating Humans and Ecological Processes in Urban Ecosystems. New York: Springer.

Alberti, M. (2016). Cities That Think Like Planets: Complexity, Resilience, and Innovation in Hybrid Ecosystems. Seattle: UW Press.

Alonso, W. (1964). Location and Land Use. Toward a General Theory of Land Rent. Cambridge, MA: Harvard University Press.

An, L. (2012). Modeling human decisions in coupled human and natural systems: review of agent-based models. Ecol. Model. 229, 30-35. doi:10.1016/j. ecolmodel.2011.10.023

Angel, S. (2012). Planet of Cities. Cambridge, MA: Lincoln Institute of Land Policy. Batty, M. (2005). Cities and Complexity: Understanding Cities through Cellular Automata, Agent-Based Models, and Fractals. Cambridge, MA: MIT Press.

Batty, M. (2013). The New Science of Cities. Cambridge, MA: MIT Press.

Bettencourt, L. M. A. (2013). The origins of scaling in cities. Science 340, 1438-1441. doi:10.1126/science. 1235823

Bettencourt, L. M. A., Lobo, J., Helbing, D., Kuhnert, C., and West, G. B. (2007). Growth, innovation, scaling, and the pace of life in cities. Proc. Natl. Acad. Sci. U.S.A. 104, 7301-7306. doi:10.1073/pnas.0610172104 uncovering fundamental laws that govern the intricate functions and dynamics of cities. Grounded in complexity theory and informed by the rapid growth and worldwide availability of high-resolution real-time empirical data, the science of cities aims to develop theoretical and practical insights that can inform decision-making and urban planning.

Diverse research disciplines, ranging from ecology and public health to sociology, political science, economics, and computer science are converging to focus significant components of their respective inquiries on the "urban." The section, Urban Science, aims to provide a forum for scholars who strive to integrate and synthesize theories, concepts, and data across multiple disciplines. The section will provide a peer-reviewed forum to advance both the science of cities and the practice of urban design and planning.

We welcome submissions that apply observational, experimental, or theoretical approaches to the study of cities, especially those employing system dynamics, network analysis, and other complex adaptive systems methods. Studies that apply data mining, simulation, and agent-based modeling are also welcome, and we encourage scholars to submit work that integrates qualitative and quantitative approaches to understanding micro-macro scale interactions, systemic effects, and emergent phenomena.

Suggested themes of inquiry for submissions to Urban Science include urban change and evolution, urban form, urban ecology, urban health, spatial inequalities, social networks, urban infrastructure, virtual mobility, shared economies, innovation, urban analytics and visualizations, indicators and dashboards, urban sensors, and big data.

\section{AUTHOR CONTRIBUTIONS}

The author confirms that she is the sole contributor to this work, and approves it for publication.

Bettencourt, L. M. A., and West, G. (2010). A unified theory of urban living. Nature 467, 912-913. doi:10.1038/467912a

Birkmann, J., Welle, T., Solecki, W., Lawsa, S., and Matthias, G. (2016). Boost resilience of small and mid-sized cities, smaller settlements are growing faster than megacities. Nature 537, 605-608. doi:10.1038/ $537605 \mathrm{a}$

Bloom, D. E., Canning, D., and Fink, G. (2008). Urbanization and the wealth of nations. Science 319, 772-775. doi:10.1126/science.1153057

Boyden, S., Millar, S., Newcombe, K., and O'Neill, B. (1981). Ecology of a City and Its People: The Case of Hong Kong. Canberra: Australian National University.

Burgess, E. W. (1925). "Can neighborhood work have a scientific basis?," in The City, eds E. Robert, E. W. Burgess, and R. D. McKenzie (Chicago: University of Chicago Press), 142-155.

Crutzen, P. J., and Stoermer, E. F. (2000). The 'Anthropocene'. IGBP Newsl. 41, $17-18$.

Ellis, E. C., Kaplan, J. O., Fuller, D. Q., Vavrus, S., Klein Goldewijk, K., and Verburg, P. H. (2013). Used planet: a global history. Proc. Natl. Acad. Sci. U.S.A. 110, 7978-7985. doi:10.1073/pnas.1217241110

Foley, R. A., and Lewin, R. (2013). Principles of Human Evolution. John Wiley \& Sons.

Forman, R. T. (2014). Urban Ecology: Science of Cities. Cambridge: Cambridge University Press.

Forrester, J. W. (1969). Urban Dynamics, Vol. 114. Cambridge: MIT Press.

Geddes, P. (1915). City in Evolution. London: Williams and Norgate. 
Glaeser, E. (2011). Triumph of the City: How Our Greatest Invention Makes Us Richer, Smarter, Greener, Healthier and Happier. New York: Penguin Books.

Grimm, N. B., Faeth, S. H., Golubiewski, N. E., Redman, C. L., Wu, J., Bai, X. M., et al. (2008a). Global change and the ecology of cities. Science 319, 756-760. doi:10.1126/science.1150195

Grimm, N. B., Foster, D., Groffman, P., Grove, J. M., Hopkinson, C. S., Nadelhoffer, K. J., et al. (2008b). The changing landscape: ecosystem responses to urbanization and pollution across climatic and societal gradients. Front. Ecol. Environ. 6:264-272. doi:10.1890/070147

Jacobs, J. (1961). The Death and Life of Great American Cities. New York: Random House.

Kitchin, R. (2014). The Data Revolution: Big Data, Open Data, Data Infrastructures \& Their Consequences. London: SAGE.

Lenzen, M., Moran, D., Kanemoto, K., Foran, B., Lobefaro, L., and Geschke, A. (2012). International trade drives biodiversity threats in developing nations. Nature 486, 109-112. doi:10.1038/nature11145

Lynch, K. (1961). The pattern of the metropolis. Daedalus 90, 79-98.

Marx, B., Stoker, T., and Suri, T. (2013). The economics of slums in the developing world. J. Econ. Perspect. 27, 187-210. doi:10.1257/jep.27.4.187

Masson, D., and Knutti, R. (2011). Spatial-scale dependence of climate model performance in the CMIP3 ensemble. J. Clim. 24, 2680-2692. doi:10.1175/2011JCLI3513.1

McDonnell, M. J., Hahs, A. K., and Breuste, J. H. (eds) (2009). Ecology of Cities and Towns: A Comparative Approach. Oxford: Cambridge University Press.

McGrath, B., and Shane, G. (2012). "Introduction: metropolis, megalopolis and metacity," in The SAGE Handbook of Architectural Theory, eds C.Crysler, S.Cairns, and H.Heynen (Londres: SAGE), 641-657.

McHale, M. R., Pickett, S. T. A., Barbosa, O., Bunn, D. N., Cadenasso, M. L., Childers, D. L., et al. (2015). The new global urban realm: complex, connected, diffuse, and diverse social-ecological systems. Sustainability 7, 5211-5240. doi:10.3390/su7055211

McPhearson, T., Parnell, S., Simon, D., Gaffney, O., Elmqvist, T., Bai, X., et al. (2016b). Scientists must have a say in the future of cities. Nature 538, 165-166. doi:10.1038/538165a

McPhearson, T., Pickett, S. T. A., Grimm, N., Niemelä, J., Alberti, M., Elmqvist, T., et al. (2016a). Advancing urban ecology towards a science of cities. Bioscience 66, 198-212. doi:10.1093/biosci/biw002

Mumford, L. (1925). The fourth migration. Surv. Graph. 7, 130-133.

Niemelä, J., and Breuste, J. H. (2011). Urban Ecology: Patterns, Processes, and Applications. Oxford: Oxford University Press.

Odum, E. P. (1971). Fundamentals of Ecology, 3rd Edn. Philadelphia: Saunders.

Odum, E. P. (1975). Ecology: The Link between the Natural and Social Sciences, 2nd Edn. New York: Holt, Rinehart, and Winston.

Park, R. E., Burgess, W. E., and Roderick, D. M. (1925). The City. Chicago: The University of Chicago Press, 239.

Pickett, S. T. A., and Zhou, W. (2015). Global urbanization as a shifting context for applying ecological science toward the sustainable city. Ecosyst. Health Sustain. 1, 5. doi:10.1890/EHS14-0014.1
Portugali, J. (2000). "Spatial cognitive dissonance and socio-spatial emergence in a self-organizing city," in Self-Organization and the City, (Berlin, Heidelberg: Springer), 141-173.

President's Council of Advisors on Science and Technology (PCAST). (2016). PCAST Report to the President on Technology and the Future of Cities.

Ratti, C., and Claudel, M. (2016). The City of Tomorrow Sensors, Networks, Hackers, and the Future of Urban Life. Yale University.

Rosenzweig, C., Solecki, W., Hammer, SA., and Mehrotra, S. (2010). Cities lead the way in climate-change action. Nature 467, 909-911.

Ross, C. (2009). Megaregions: Planning for Global Competitiveness. Washington, DC: Island Press.

Ruddiman, W. F. (2013). The Anthropocene. Annu. Rev. Earth Planet. Sci. 41, 45-68. doi:10.1146/annurev-earth-050212-123944

Seto, K. C., Reenberg, A., Boone, C. G., Fragkias, M., Haase, D., Langanke, T., et al. (2012). Urban land teleconnections and sustainability. PNAS 109, 7687-7692. doi:10.1073/pnas.1117622109

Solecki, W., Seto, K. C., and Marcotullio, P. (2013). It's time for an urbanization science. Environment 55, 12-16. doi:10.1080/00139157.2013.748387

Steffen, W., Richardson, K., Rockström, J., Cornell, S. E., Fetzer, I., Bennett, E. M., et al. (2015). Planetary boundaries: guiding human development on a changing planet. Science 347, 1259855. doi:10.1126/science.1259855

Townsend, A. M. (2013). Smart Cities: Big Data, Civic Hackers and the Quest for a New Utopia. New York: W.W. Norton \& Co.

UN-Habitat. (2008). State of the World's Cities 2008/2009: Harmonious Cities. London: Earthscan Publications.

UN-Habitat. (2016). World Cities Report. United Nations Human Settlements Programme.

Verburg, P. H., Dearing, J. A., Dyke, J. G., van der Leeuw, S., Seitzinger, S., Steffen, W., et al. (2016). Methods and approaches to modelling the Anthropocene. Glob. Environ. Change 39, 328-340. doi:10.1016/j.gloenvcha. 2015.08.007

Victor, D. (2015). Climate change: embed the social sciences in climate policy. Nature 520, 27-29. doi:10.1038/520027a

Young, O. R., Berkhout, F., Gallopin, G. C., Janssen, M. A., Ostrom, E., and van der Leeuw, S. (2006). The globalization of socio-ecological systems: an agenda for scientific research. Glob. Environ. Change 16, 304-316. doi:10.1016/j. gloenvcha.2006.03.004

Conflict of Interest Statement: The author declares that the research was conducted in the absence of any commercial or financial relationships that could be construed as a potential conflict of interest.

Copyright (c) 2017 Alberti. This is an open-access article distributed under the terms of the Creative Commons Attribution License (CC BY). The use, distribution or reproduction in other forums is permitted, provided the original author(s) or licensor are credited and that the original publication in this journal is cited, in accordance with accepted academic practice. No use, distribution or reproduction is permitted which does not comply with these terms. 